\title{
Application of smart power grid in developing countries
}

\begin{abstract}
Smart grid, which is extensively new topic, is the next generation of power grid. Future modern grid will manage all parts of electrical power grid from generation to transmission and distribution by using intelligent methods. Smart grid progress in some developing countries is same to developed ones. In other parts of developing world, research works and pilot projects are newly started. Therefore, in the present work, a study of applied efforts in developing countries by regarding infrastructure of smart grid works was proposed. The analyses show that some countries like China, India and Brazil are pioneer on smart grid in developing world. As a conclusion, a progress pattern based on smart grid development in these three countries is proposed.
\end{abstract}

Keyword: Developing countries; Power grid; Smart grid 